\title{
Comparison of Saponin Content and Antioxidant Effect depending on the Processing Method of Codonopsis lanceolata
}

\author{
Eun Young Kim ${ }^{1, *}$, Jeong Wook Jeon ${ }^{2, * *}$ and Kyung-Yae Hyun ${ }^{3, \dagger ; *}$ \\ ${ }^{1}$ Department of Biomedical Laboratory Science, Songho University, Hoengseong 25242, Korea \\ ${ }^{2} R \& D$ Center, Nutricare Co., Ltd., Hoengseong 25242, Korea \\ ${ }^{3}$ Department of Clinical Laboratory Science, Dong-Eui University, Busan 47340, Korea
}

\begin{abstract}
Codonopsis lanceolata, called deodeok in Korean, has been verified for various effects, including anti-aging and antiinflammatory effects and insomnia improvement, and is one of the healthy foods that Koreans enjoy eating. In this study, the saponin content, lansemaside A content, and total saponin content of deodeok were analyzed using high-pressure sterilization and solid fermentation by mixed lactic acid bacteria. The antioxidant effect was compared to determine improved processing methods of deodeok. The lansemaside A content of deodeok samples depending on the preprocessing methods was analyzed: $2,594.10 \mathrm{mg} / \mathrm{kg}$ for dried deodeok, $2,100.93 \mathrm{mg} / \mathrm{kg}$ for steamed deodeok, and 1,151.31 mg/kg for fermented deodeok. The total saponin content was found to be 7,209 mg/kg for dried deodeok and 8,605 mg/kg for steamed deodeok, showing a high saponin content. The total polyphenol content was highest for dried deodeok, steamed deodeok, and fermented deodeok. As for the antioxidant effect, it was analyzed that the effect of dried deodeok was the highest, followed by steamed deodeok and fermented deodeok; Dried deodeok had the highest value in total polyphenol content, not in total saponin content, which is considered to have a positive influence on its antioxidant effect. The content of lansemaside A was the highest for dried deodeok. When fermented deodeok is consumed, more beneficial effects on health can be expected by ingesting it with lactic acid bacteria cultured using saponins and polyphenols. Therefore, this study suggests the possibility of manufacturing products suitable for the needs of consumers, such as the flavor of deodeok, according to the processing methods.
\end{abstract}

Key Words: Codonopsis lanceolata, Deoduck, Lancemaside A, Total saponin, Total polyphenol content, Antioxidant effect

\section{서 론}

세포의 산화적 스트레스는 생체 내 세포대사과정이나 여러 환경오염 및 화학물질의 노출 등에 의해 생성된 과산화수소(hydrogen peroxide, $\mathrm{H}_{2} \mathrm{O}_{2}$ ), 하이드록시 라디칼 (hydroxyl radicals, $\cdot \mathrm{OH}$ ) 등의 활성산소종(reactive oxygen species, ROS)에 의해 유발된다고 알려져 있다. 산화적 스
트레스는 세포체내에 세포막 손상과, 지질 산화 등을 초 래하여 암, 심장질환, 뇌혈관 질환과 같은 만성질환을 발 생할 수 있기 때문에 최근에 항산화 활성이 높고 인체에 무해한 성분을 찾으려는 시도가 진행되고 있다(Jeon et al., 2013).

더덕(Codonopsis lanceolata)은 다년생 초본의 덩굴성 식 물로 초롱꽃과에 속한다. 더덕은 일반적으로 우리나라 전 지역에서 재배가 가능하고 우리나라뿐만 아니라 중국, 일

Received: November 22, 2021 / Revised: December 1, 2021 / Accepted: December 1, 2021

${ }^{*}$ Professor, ${ }^{* *}$ Researcher.

${ }^{\dagger}$ Corresponding author: Kyung-Yae Hyun. Department of Clinical Laboratory Science, Dong-Eui University, Busan 47340, Korea. Tel: 82-51-890-2683, Fax:+82-0505-182-6877, e-mail: kyhyun@deu.ac.kr (C) The Korean Society for Biomedical Laboratory Sciences. All rights reserved.

(C) This is an Open Access article distributed under the terms of the Creative Commons Attribution Non-Commercial License (http://creativecommons.org/licenses/by-nc/3.0/) which permits unrestricted non-commercial use, distribution, and reproduction in any medium, provided the original work is properly cited. 
본, 등지에 분포되어 있다(Hwang et al., 2011). 더덕은 전 통적으로 진해, 거담, 두통에 효과가 있는 것으로 알려져 있고, 한방에서는 한기와 열병, 경련, 인두염 등에 사용된 천연 강장제로도 잘 알려져 있으며 최근에는 현대인들의 주요 관심인 사포닌, 폴리페놀과 같이 노화를 예방하는 항산화성분을 포함하고 있다(Lee et al., 2002; Ichikawa et al., 2009; Jeon et al., 2013).

사포닌은 더덕의 대표적인 약효성분으로 알려져 있으며 한국산 더덕에 7종의 사포닌인 lacemaside A, lancemaside B, lancemaside $\mathrm{C}$, lancemaside $\mathrm{E}$, lancemaside $\mathrm{G}$, foetidissimoside $\mathrm{A}$, aster saponin $\mathrm{Hb}$ 가 존재하는 것으로 알려져 있다(In et al., 2019). 그 중 lacemasides A는 비만 예방, 대장염 완화, 기억력 및 불면증 개선, 항염증 등에도 효과가 있는 것으 로 보고되고 있어 소비자들의 관심이 증가하는 추세이다 (Hong et al., 2006). 또한 lancemaside A는 체내에서 echinocystic acid로 대사되는데 이는 echinocystic acid가 해마를 자극해서 기억관련 신호분자의 인산화 수준을 증가시키 는 것으로 알려져 있다(Lim, 2015). 이 echinocystic acid는 인지기능 장애의 대표적인 질환인 치매를 개선하는데 도 움을 줄 것으로 기대되고 있다(Jung et al., 2018).

폴리페놀은 녹색식물의 광합성 작용에 의해 생성된 일 부의 당이 2 차대사산물로 벤젠고리 $\left(\mathrm{C}_{6} \mathrm{H}_{6}\right)$ 의 수소 중 하나 가 수산시로 치환된 물질인 페놀이 2 개 이상을 갖고 있 는 물질이다. 과일과 야채, 차류와 같은 식품에 함유되어 있는 천연 화합물로 자외선, 활성산소 등과 같은 외부의 환경으로부터 보호하는 역할을 하는 식물체의 2 차 대사 산물로써 알려져 있다. 폴리페놀 화합물이 풍부한 식품 은 항산화 항균 항암과 관련된 효과를 보여 장기간 섭취 하면 심혈관 질환, 당뇨병, 신경 퇴행성질환의 발병의 예 방효과를 나타내는 것으로 알려져 기능성 식품으로 주목 받고 있다(Jeong et al., 2017; Lee and Lee, 2018).

더덕의 약리 활성 성분의 함량을 증가시키기 위한 방 법으로 초고압, 발효 등의 가공방법 등이 연구되고 있다. 초고압 공정은 비가열처리 가공방법으로 식품의 보존성, 물성 기능성을 향상시켜 줄 뿐 아니라 성분을 변성시키 지 않고 신선감을 유지시킬 수 있는 가공기술로 알려져 있다(Bennett and Marquis, 1998; Shouqin et al., 2004; Deliza et al., 2005; Kim et al., 2010). 초고압 공정은 다른 식품의 보 존성과 기능성을 향상시킬 수 있고 압력을 이용해 물과 오일을 순간적으로 균일하게 전달시켜 다른 공정에 비해 화학변화가 일어나지 않는다. 단시간 내에 추출할 수 있 고, 불순물이 적게 거의 없어 고순도의 단일 성분 추출물
을 얻을 수 있는 장점이 있다(Park et al., 2010; Seo et al., 2011; Jeon et al., 2013).

발효 공정은 일반적으로 미생물이나 균류 등을 이용해 사람에게 유용한 물질을 얻어내며, 산소를 사용하지 않고 에너지를 얻는 당 분해과정으로 식품의 향, 풍미, 조직감 과 저장성을 향상시킨다. 또한 식품의 발효과정을 통하여 독성물질 파괴, 생리활성 물질 생산 및 소화성을 증진시 키는 것으로 알려져 있다(Lee et al., 2004; Kim et al., 2009). 더덕의 가공 기술로 주로 이용되고 있는 초고압, 발효 등 은 약리 활성 성분의 함량을 증가시키기는 하지만, 초고 압 공정은 산업화 관점에서는 배치 타입으로 제조하여야 하며, 관리에 있어서 많은 시간이 소요되며, 미생물 오염 의 정도를 줄일 수 있으나 멸균과 같은 효과를 가져오지 못하며 진균류에 대한 관리에 어려움이 있을 수 있다. 발 효 공정에서도 어떤 종균을 사용하느냐에 따라 활성 성 분의 함량 차이를 가져올 수 있어 다양한 실험 조건을 설정하여야 하여야 한다(Kwak and Chang, 2001).

본 연구에서는 이러한 단점을 보완하고자 기존의 선행 연구에서 살펴보지 않은 방법인 고압멸균 방법과 혼합유 산균에 의한 고체 발효 방법을 이용해 최근에 주목 받고 있는 더덕 사포닌 lancemaside A 함량, 총 사포닌 함량, 총 폴리페놀 함량 분석 및 항산화 효과를 비교 분석하여 항 산화 효과가 향상된 더덕의 새로운 가공 공정의 가능성 을 확인하고자 하였다.

\section{재료 및 방법}

\section{시약 및 재료}

더덕은 강원도 횡성군 청일면 농협을 통하여 2020년 7월에 농가로부터 수매한 생더덕을 구매하였다. 찐 더덕 과 발효 더덕 시료를 만들기 위해 구매한 더덕 중에서 상태가 양호한 생더덕 10 개를 선별하여 각각의 가공 공 정을 거쳐서 최종 분말 시료 형태로 만들어 혼합하여 사 용하였다.

\section{건 더덕 분말의 제조}

생더덕을 껍질을 제거 후 흐르는 물에 세척 후 열풍 건조하여 건더덕을 만들었다. 건조된 생더덕을 $60^{\circ} \mathrm{C}$ 에 서 증류수를 가해서 10 시간을 열수추출하였으며 추출액 을 여과지(N0. 2, Whatman, Japan)을 사용하여 여과하였으 며 상등액을 감압농축기로 농축하였으며 농축한 더덕을 분말화하여 실험에 사용하였다. 


\section{찐 더덕 분말의 제조}

생더덕을 껍질을 제거 후 흐르는 물에 세척 후 $121^{\circ} \mathrm{C}$, 10 분의 가공 조건으로 더덕을 고압열처리를 하여 찐더덕 을 만들었다. 이를 $50^{\circ} \mathrm{C}, 10$ 시간 열풍 건조를 통하여 최종 적으로 건조 형태의 더덕을 얻어 분말화하여 실험에 사 용하였다. 이에 대한 대조군으로서 건더덕을 사용하였다.

\section{발효 더덕 분말의 제조}

생더덕을 껍질을 제거 후 흐르는 물에 세척 후 혼합유 산균을 생더덕 기준 $1 \%(\mathrm{w} / \mathrm{w})$ 적용하여 고체 발효 $\left(40^{\circ} \mathrm{C}\right.$, 10 시간)를 진행하여 $70^{\circ} \mathrm{C}, 5$ 분 열처리하여 이를 $50^{\circ} \mathrm{C}, 10$ 시 간 열풍 건조를 통하여 최종적으로 건조 형태의 유산균 고체 발효 더덕을 얻어 분말화하여 실험에 사용하였다.

고체 발효에 사용한 유산균은 현재 온라인 판매되고 있는 $\mathrm{M}$ 사의 리얼 카스피 그릭요거트 스타터 제품을 사용하였으며, 여기에는 주요 유산균으로 Lactobacillus acidophilus, Bifidobacterium lactis, Streptococcus thermophilus, Lactobacillus delbrueckii subsp. bulgaricus, Lactobacillus plantarum을 포함하고 있으며, 건강기능식품공전의 건강기능 식품 시험법에 따른 유산균 실험 결과 $35 \sim 37^{\circ} \mathrm{C}$ 에서 유산 균 수는 $1.9 * 10^{7} \mathrm{cfu} / \mathrm{g}$ 수준으로 함유되어 있는 혼합유 산균으로 고체 발효를 하였다(Fig. 1).

\section{더덕 시료의 사포닌 lansemaside A 성분 분석}

성분 분석을 위해 LC-MS/MS 장비(Thermo Scientific TSQ ALTIS, USA)를 활용하였다. 더덕 사포닌 lansemaside $\mathrm{A}$ 표준물질은 국립농업과학원을 통하여 구하였다. 이를 표준원액 lansemaside $\mathrm{A}$ 로 제조하였고, 총 폴리페놀, 총 사 포닌 분석을 위하여 3 차 증류수로 각각의 시료를 추출 후 $70 \%$ 메탄올로 단계 희석하여 최종적으로 $0.2 \mu \mathrm{m}$ 필 터로 여과하여 시료를 준비하였다. 이 때 사용한 컬럼은 Waters BEH C18 $(2.1 \mathrm{~mm} \times 100 \mathrm{~mm} \times 1.7 \mu \mathrm{m})$, 컬럼 오 븐 온도는 $40^{\circ} \mathrm{C}$, injection volume은 $5 \mu \mathrm{L}$, 이동상은 $70 \% \mathrm{~A}$ 용매( $0.1 \%$ Formic acid in water)와 $30 \%$ B 용매 $(0.1 \%$ formic acid in Acetonitrile)로 평형화시킨 ODS-AM C18 column $(4.6 \times 250 \mathrm{~mm}, 5 \mu \mathrm{m}, \mathrm{YBM}, \mathrm{USA})$ 에 시료 $5 \mu \mathrm{L}$ 를 주입한 후 유속 $01.0 \mathrm{~mL} / \mathrm{min}$ 를 유지하며 용매 $\mathrm{B}$ 의 농도구배로 용출시켰다. 용출조건은 $0 \mathrm{~min}: 70 \mathrm{~A} / 30 \mathrm{~B}, 35 \mathrm{~min}$ : 60A/40B, $37 \mathrm{~min}: 60 \mathrm{~A} / 40 \mathrm{~B}, 40 \mathrm{~min}$ : $70 \mathrm{~A} / 30 \mathrm{~B}, 50 \mathrm{~min}: 70 \mathrm{~A} / 30 \mathrm{~B}$ 이였 다. 유속은 $0.25 \mathrm{~mL} / \mathrm{min}$ 를 유지하며 용매 $\mathrm{B}$ 의 농도구배로 용출시켰다.

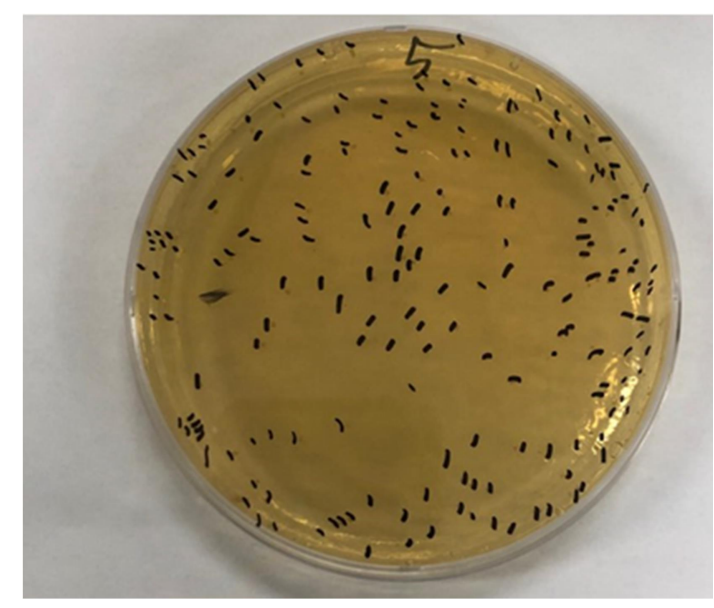

Fig. 1. Mixed Lactobacillus colonies in the nutrient agar.

\section{더덕 시료의 총 사포닌 성분 분석}

더덕의 총 사포닌(total saponin) 분석법은 더덕을 40 메 쉬 크기로 분쇄하여 사포닌 성분을 $80 \%$ 메탄올로 추출 하였다. 시험용액 $100 \mu \mathrm{L}$ 을 정확히 취하여 시험관에 넣고 얼음물 속에서 $8 \%$ 바닐린-에탄올 용액 $0.3 \mathrm{~mL}$ 과 $72 \%$ 황 산 용액 $4 \mathrm{~mL}$ 을 첨가하였다. 시험관을 $60^{\circ} \mathrm{C}$ 항온 수조에 넣고 10 분간 가온하여 내용액을 발색시킨 후 $545 \mathrm{~nm}$ 에서 분광도를 측정하였으며 ginsenoside-Re를 표준물질로 사용 하였다.

시료에 함유되어 있는 총 사포닌 함량(Y)은 다음 식에 준하여 계산하였다.

$$
\mathrm{Y}(\%)=\mathrm{Y}^{\prime} \times\{(\mathrm{T} / \mathrm{V}) / \mathrm{W}\} \times 100
$$

Y': 시험용액의 분광도를 검량선에 대입하여 구한 양 $(\mathrm{mg})$

$\mathrm{T}$ : 사포닌 추출액을 정용한 부피 $(\mathrm{mL})$

$\mathrm{V}$ : 분광도 측정 시 취한 부피 $(\mu \mathrm{L})$

$\mathrm{W}$ : 시료 채취량 $(\mathrm{mg})$

\section{더덕 시료의 총 폴리페놀 성분 분석}

총 플라페놀 함량은 Zhishen 등 (Zhishen et al., 1999)과 Singleton 등 (Singleton et al., 1999)의 방법을 응용하여 측 정하였다. 각 시료 $20 \mu \mathrm{L}$ 를 sodium nitrite solution $75 \mu \mathrm{L}$ 와 3 차 증류수 $100 \mu \mathrm{L}$ 를 혼합하여 6 분간 반응시키고 aluminum chloride solution $20 \mu \mathrm{L}$ 를 첨가하여 다시 5 분간 반응시킨 후 $1 \mathrm{M} \mathrm{NaOH} 40 \mu \mathrm{L}$ 와 섞어 $510 \mathrm{~nm}$ 에서 흡광도 를 측정하였다. 표준물질 quercetin을 사용하여 시료와 동 일한 방법으로 분석하여 검량선을 작성한 후 총 플리페 
Table 1. Contents of lancemaside A and total saponin by dried deouck, steamed deodeok, fermented deodeok

\begin{tabular}{lccc}
\hline \hline \multicolumn{1}{c}{$(\mathrm{mg} / \mathrm{kg})$} & $\begin{array}{c}\text { Dried } \\
\text { deodeok }\end{array}$ & $\begin{array}{c}\text { Fermented } \\
\text { deodeok }\end{array}$ & $\begin{array}{c}\text { Steamed } \\
\text { deodeok }\end{array}$ \\
\hline Lancemaside A & 2594.1 & 1151.31 & 2100.93 \\
Total saponin & 7,209 & 5,057 & 8,605 \\
\hline
\end{tabular}

놀 함량을 산출하였다. 실험은 3 회 반복 수행하여 평균값 을 나타내었다.

\section{더덕 시료의 항산화 능력 측정}

$\mathrm{DPPH}$ 에 대한 수소공여 효과로 측정하는 라디칼 소거 능은 Blois (Blois, 1958)의 방법을 변형하여 측정하였다. 일정 농도로 희석된 시료 $40 \mu \mathrm{L}$ 와 $1.5 \times 10^{4} \mathrm{M}$ 의 농도로 $\mathrm{DPPH}$ 를 absolute methanol에 희석한 용액 $160 \mu \mathrm{L}$ 를 가하 여 잘 혼합한 후 암소에서 30 분간 반응시킨 후 $518 \mathrm{~nm}$ 에 서 흡광도를 측정하였다. 결과 값은 추출물 첨가구와 무 첨가구를 비교하여 라디칼의 소거활성을 백분율(\%)로 나 타내어 농도에 따른 DPPH 라디칼 소거능을 확인하였다.

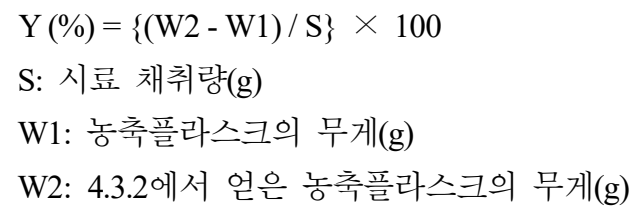

\section{결과 및 고찰}

\section{더덕 시료의 전처리에 따른 lansemaside $A$ 함량과 총 사포닌 함량 분석}

생더덕을 건더덕, 찐더덕, 발효 더덕으로 각각 전처 리하여 시료를 만들어 고형분 기준으로 더덕의 사포닌 lansemaside A 성분을 분석하였다(Table 1). 더덕 사포닌으 로서 lansemaside A 건더덕은 $2,594.10 \mathrm{mg} / \mathrm{kg}$, 찐더덕은 $2,100.93 \mathrm{mg} / \mathrm{kg}$, 발효더덕은 $1,151.31 \mathrm{mg} / \mathrm{kg}$ 으로 분석되었 으며, 건더덕, 찐더덕, 발효더덕 순으로 감소하는 경향을 보였다. 이에 대해서는 즉 발효 공정과 열처리 공정을 통 해서 lansemaside $\mathrm{A}$ 는 다른 형태로 전환이 되는 것으로 추 정해볼 수 있다. 그 이유는 총 사포닌 함량을 분석하였을 때 발효더덕에서 $5,057 \mathrm{mg} / \mathrm{kg}$, 건더덕에서 $7,209 \mathrm{mg} / \mathrm{kg}$, 찐더덕에서 $8,605 \mathrm{mg} / \mathrm{kg}$ 함량으로 분석되었으며, 전체적으 로 찐더덕의 총 사포닌 함량이 증가하는 경향을 보였다. lansemaside A가 전처리 공정을 통해 다른 사포닌 형태로
Table 2. Contents of total polyphenol by dried deouck, steamed deodeok, fermented deodeok

\begin{tabular}{cccc}
\hline \hline$(\mathrm{mg} / \mathrm{kg})$ & $\begin{array}{c}\text { Dried } \\
\text { deodeok }\end{array}$ & $\begin{array}{c}\text { Fermented } \\
\text { deodeok }\end{array}$ & $\begin{array}{c}\text { Steamed } \\
\text { deodeok }\end{array}$ \\
\hline Total polyphenol & 5,548 & 3,761 & 4,480 \\
\hline
\end{tabular}

전환된 것으로 유추할 수 있다.

\section{더덕 시료의 전처리에 따른 총 폴리페놀 함량 분석}

폴리페놀은 식물의 대표적인 이차대사산물로서 항산 화 작용, 항균 작용, 항알레르기 및 항암 효과에 관여하 는 것으로 알려져 있다(Rice-Evans et al., 1997; Perron and Brumaghim, 2009). 가공 공정에 따른 더덕 추출물의 총 폴 리페놀 함량을 분석한 결과 Table 2 와 같이 건더덕 > 찐 더덕 > 발효더덕 순으로 높게 나타났다. 이전에 가공공 정에 따른 더덕 추출물의 항산화 활성(Jeon et al., 2013)에 의한 실험 결과 의하면 생더덕보다 가공 처리한 더덕에서 폴리페놀 함량이 모두 증가한다는 보고와 반대의 결과를 얻었다. 즉, 발효 공정과 고압 열처리 조건에 따라 폴리 페놀 함량은 조절 가능하다고 해석되어진다. Table 3 에 나 와있는 식물 유래 추출물 125 종의 지표성분을 가지고 건 더덕, 찐더덕, 발효더덕에 대해 폴리페놀 종류에 대한 스 크리닝을 하였다. 그 결과 Table 4에서와 같이 지표성분으 로서 클로로겐산의 경우 건더덕 > 찐더덕 > 발효더덕 순 으로 함량이 분석되었다. 다른 폴리페놀의 지표성분으로 서 건더덕에서 함량이 높은 성분은 카페인산, 쿠마린산, 페룰릭산, 시린직산, 갈릭산, 프로토카테츄익산이 상대적 으로 높게 나타났고, 발효더덕에서 함량이 상대적으로 높 은 성분은 헤스페리딘이 있었으며, 찐더덕에서 상대적으 로 높은 성분은 살리실릭산이 있었다(Table 5).

\section{더덕 시료의 전처리에 따른 항산화 효과 분석}

Table 3의 실험 결과에서 총 폴리페놀, 총사포닌의 차이 에 의해 항산화효과를 비교해 보면 항산화효과가 가장 좋은 순서로서 건더덕 > 찐더덕 > 발효더덕 순서로 나타 났으며, 총사포닌보다는 총 폴리페놀의 함량이 건더덕에 서 가장 많아서 항산화효과에 긍정적으로 작용한 것으로 사료된다(Table 6). 본 연구결과에 따르면 더덕을 섭취하 는 방법으로 건더덕이 항산화효과 측면에서 가장 효과가 좋을 것으로 보인다. 건더덕은 다른 더덕보다 항산화 효 과가 높아 더덕을 섭취하거나 가공할 때 또는 보존성을 증가시는 방법으로서 건조시키는 방법을 이용하면 더 건 
Table 3. Indicator ingredients of 125 plant derived extracts of dried deouck, steamed deodeok, fermented deodeok

\begin{tabular}{|c|c|c|c|c|c|}
\hline No & Ingredients & No & Ingredients & No & Ingredients \\
\hline 1 & 10-Hydroxy-2-decenoic acid & 43 & Epoxybergamottin & 85 & Naringin \\
\hline 2 & 3-Acetyl-11-koto- $\beta$-boswellic acid & 44 & Eupatilin & 86 & Narirutin \\
\hline 3 & 4-o-Feruloylquinic acid & 45 & Ferulic acid & 87 & Neohesperidin \\
\hline 4 & $\beta$-Boswellic acid & 46 & Formononetin & 88 & Nodakenetin \\
\hline 5 & D-Luciferin & 47 & GABA & 89 & Nodakenin \\
\hline 6 & $\varepsilon$-Viniferin & 48 & Galangin & 90 & Nodosin \\
\hline 7 & p-Coumaric acid & 49 & Gallic acid & 91 & Nordihydroguaiaretic acid \\
\hline 8 & Acacetin & 50 & Ganoderic acid & 92 & Ombuoside \\
\hline 9 & Aleuritic acid & 51 & Genistein & 93 & Oxymatrine \\
\hline 10 & Allantoin & 52 & Genistin & 94 & Oxypeucedanin \\
\hline 11 & Apigenin & 53 & Glycitein & 95 & Paeoniflorin \\
\hline 12 & Artemisinin & 54 & Glycitin & 96 & Parthenolide \\
\hline 13 & Artepillin C & 55 & Glycyrrhizin & 97 & Phloretin \\
\hline 14 & Asiaticoside & 56 & Hamamelitannin & 98 & Phlorizin \\
\hline 15 & Astragalin & 57 & Hesperidin & 99 & Phloroglucinol \\
\hline 16 & Astragaloside IV & 58 & 1Hispidulin & 100 & Pinocembrin \\
\hline 17 & Baicalein & 59 & Honokiol & 101 & Poncirin \\
\hline 18 & Baicalin & 60 & Hydroxy alpha Sanshool & 102 & Protocatechuic acid \\
\hline 19 & Bakuchiol & 61 & Hyperforin & 103 & Pterostilbene \\
\hline 20 & Berberine & 62 & Hyperoside & 104 & Quercetin \\
\hline 21 & Bergamottin & 63 & Icariin & 105 & Resveratrol \\
\hline 22 & Bergapten & 64 & Isopimpinellin & 106 & Rhamnetin \\
\hline 23 & Biochanin A & 65 & Isoquercitrin & 107 & Rosavin \\
\hline 24 & Bixin & 66 & Isosakuranetin & 108 & Rosmarinic acid \\
\hline 25 & Byakangelicol & 67 & Kaempferol & 109 & Rut \\
\hline 26 & Caffeic acid & 68 & Kakklide & 110 & Sakuranetin \\
\hline 27 & Caffein & 69 & Kavain & 111 & Sakuranin \\
\hline 28 & Capsaisin & 70 & Lancemaside A & 112 & Salicylic acid \\
\hline 29 & Catechin & 71 & Leonurine & 113 & Sapindoside A \\
\hline 30 & Chalcon & 72 & Levistilide A & 114 & Shikonin \\
\hline 31 & Chlorogenic acid & 73 & Linarin & 115 & Silibinin \\
\hline 32 & Cinnamic acid & 74 & Liquiritigenin & 116 & Sinapic acid \\
\hline 33 & Curcumin & 75 & Liquiritin & 117 & Sophoridine \\
\hline 34 & Daidzein & 76 & Loganin & 118 & Sulforaphane \\
\hline 35 & Daidzin & 77 & Lovastatin & 119 & Syringic acid \\
\hline 36 & Decursin & 78 & Lucidone B & 120 & Theobromine \\
\hline 37 & Ellagic acid & 79 & Luteolin & 121 & Vanillic acid \\
\hline 38 & Emodin & 80 & Madecassoside & 122 & Vitexin \\
\hline 39 & Epicatechin & 81 & Magnolol & 123 & Withaferin A \\
\hline 40 & Epicatechin gallate & 82 & Matrine & 124 & Withanolide \\
\hline 41 & Epigallocatechin gallate & 83 & Myricetin & 125 & Xantotoxin \\
\hline 42 & Epigallocatechin & 84 & Myricitrin & & \\
\hline
\end{tabular}


Table 4. Contents of chlorogenic acid by dried deouck, steamed deodeok, fermented deodeok

\begin{tabular}{lccc}
\hline \hline & $\begin{array}{c}\text { Dried } \\
\text { deodeok }\end{array}$ & $\begin{array}{c}\text { Fermented } \\
\text { deodeok }\end{array}$ & $\begin{array}{c}\text { Steamed } \\
\text { deodeok }\end{array}$ \\
\hline Chlorogenic acid & 255.66 & 43.69 & 199.37 \\
\hline
\end{tabular}

Table 5. Contents of each polyphenol by dried deouck, steamed deodeok, fermented deodeok

\begin{tabular}{lccc}
\hline \hline \multicolumn{1}{c}{$(\mathrm{mg} / \mathrm{kg})$} & $\begin{array}{c}\text { Dried } \\
\text { deodeok }\end{array}$ & $\begin{array}{c}\text { Fermented } \\
\text { deodeok }\end{array}$ & $\begin{array}{c}\text { Steamed } \\
\text { deodeok }\end{array}$ \\
\hline Caffeic acid & 2.83 & 1.16 & 1.64 \\
p-coumaric acid & 2.11 & 1.01 & 0.2 \\
Ferulic acid & 2.26 & 1.14 & 0.4 \\
Salicylic acid & 0.3 & 0.18 & 0.57 \\
Syringic acid & 1.24 & 0.63 & 0.43 \\
Gallic acid & 0.3 & 0 & 0 \\
Hesperidin & 0 & 0.66 & 0 \\
Protocatechuic acid & 2.49 & 1.01 & 1.4 \\
\hline
\end{tabular}

Table 6. Contents of DPPH by dried deouck, steamed deodeok, fermented deodeok

\begin{tabular}{lccc}
\hline \hline & $\begin{array}{c}\text { Dried } \\
\text { deodeok }\end{array}$ & $\begin{array}{c}\text { Fermented } \\
\text { deodeok }\end{array}$ & $\begin{array}{c}\text { Steamed } \\
\text { deodeok }\end{array}$ \\
\hline DPPH (\%) & $1.8 \%$ & $6.8 \%$ & $4.8 \%$ \\
\hline
\end{tabular}

Abbreviation: DPPH, $\alpha$-diphenyl- $\beta$-picrylhydrazyl

강에 유용한 식품이 될 것이다. 즉, 건강기능식품 소재로 건더덕을 분말 형태로 이용하여 호흡기질환을 예방하고 인지능력을 개선시킬 수 있을 것이다.

또한 lansemaside A가 건더덕에서 가장 함량이 높은 반 면 총 사포닌 함량은 찐더덕에서 높다는 것은 고압열처 리 조건에서 란세마사이드 A가 다른 사포닌 형태로 전환 된 것으로 유추할 수 있다. 이후 더 많은 연구를 통하여 더덕을 고압열처리를 했을 경우 증가되는 사포닌 중 유 용한 사포닌을 선별하여 새로운 식품 소재와 지표물질로 서 개발할 수 있을 것이다.

발효공정을 통해 lansemaside A, 총사포닌, 총폴리페놀 함량이 모두 감소한다는 것을 본 연구의 결로 알 수 있 듯이 특정 유산균에 의해 더덕 사포닌과 폴리페놀이 사 용된 것으로 사료된다. 즉, 발효더덕을 섭취 시 사포닌과 폴리페놀을 이용하여 배양된 유산균을 함께 섭취함으로 써 건강에 유용한 효과를 기대할 수 있을 것이다. 또한 일상 생활에서 더덕을 쉽게 이용할 수 있는 방법으로써
고유의 강한 더덕 풍미를 좋아하지 않는 소비자에게 도 움을 줄 수 있으며, 부드러운 물성을 가진 식품이 개발될 수 있다는 것을 시사하고 있다.

더덕의 유용성분을 증대시키기 위한 가공방법으로서 고압처리와 발효 공정에 대해서는 공정 최적화를 통한 추가 연구가 필요하다고 생각한다.

\section{ACKNOWLEDGEMENT}

This work was supported by the research fund of Songho University (SH-2020-A).

\section{CONFLICT OF INTEREST}

The authors declare that they have no conflict of interest.

\section{REFERENCES}

Bennett PB, Marquis RE. High pressure biology and medicine 1998. 1-428 University of Rochester Press, New York, NY USA.

Blois MS. Antioxidant determinations by the use of a stable free radical. Nature. 1958. 181: 1199-1200.

Deliza R, Rosenthal A, Abadio F, Silva CH, Castillo C. Application of high pressure technology in the fruit juice processing: Benefits perceived by consumers. Journal of Food Engineering. 2005. 67: 241-246.

Hong WS, Lee JS, Ko SY, Choi YS. A study on the perception of Codonopsis lanceolata dishes and the development of Codonopsis lanceolata dishes. Korean Journal of Food and Cookery Science. 2006. 22: 181-192.

Hwang CR, Oh SH, Kim HY, Lee SH, Hwang IG, Shin YS, Lee JS, Jeong HS. Chemical composition and antioxidant activity of deoduk (Codonopsis lanceolata) and doragi (platycodon grandiflorum) according to temperature. Journal of the Korean Society of Food Science and Nutrition. 2011. 40: 798-803.

Ichikawa M, Ohta S, Komoto N, Ushijima M, Kodera Y, Hayama M, Shirota O, Sekita S, Kuroyanagi M. Simultaneous determination of seven saponins in the roots of Codonopsis lanceolata by liquid chromatography-mass spectrometry. Journal of Natural Medicines. 2009. 63: 52-57.

In SU, Min JL, Ju HN, Il RR. Effects of Additional Fertilization after Cultivating Green Manure Crops on the Growth and Saponin Content of Codonopsis lanceolata Trautv. Korean J Medicinal Crop Sci. 2019. 27: 1-8. 
Jeong IH, Oh MS, Jeon JS, Kim HT, Hong SR, Park KH, Yoon MH. A Comparative Study on Anthocyanin and Polyphenol Contents in Colored Agricultural Products. Journal of Food Hygiene and Safety. 2017. 32: 371-380.

Jeon SM, Kim SY, Kim IH, Go JS, Kim HR, Jeong JY, Lee HY, Park DS. Antioxidant activities of processed deoduck (Codonopsis lanceolata) extracts. J Korean Soc Food Sci Nutr. 2013. 42: 924-932.

Jung WY, Kim H, Jeon SJ, Park HJ, Choi HJ, Kim NJ, Kim DH, Jang DS, Ryu JH. Eclalbasaponin ii ameliorates the cognitive impairmentinduced by cholinergic blockade in mice. Neurochemical Research. 2018. 43: 351-362.

Kim GY, Yang YS, Youn JY, Lee CJ, Jeon JW, Jung OS, Choi YH. Theory and Practice of Fermented Food. Kyomunsa Seoul, Korea. p.12. 2009.

Kim NY, Chae HS, Lee IS, Kim DS, Seo KT, Park SJ. Analysis of Chemical Composition and Antioxidant Activity of Codonopsis lanceolata Skin. J Korean Soc Food Sci Nutr. 2010. 11: 16271633.

Kwak YS, Chang JK. Effect of various sterilization methods on growth of microorganism contaminated in ginseng powder. Journal of Food Hygiene and Safety. 2001. 16: 221-226.

Lee KT, Choi J, Jung WT, Nam JH, Jung HJ, Park HJ. Structure of a new echinocystic acid bisdesmoside isolated from Codonopsis lanceolata roots and the cytotoxic activity of prosapogenins. Journal of Agricultural and Food chemistry. 2002. 50: 41904193.

Lee SB, Go GH, Yang JY, Oh SH, Kim JG. Fermented food. 2nd. Kyomunsa, Seoul, Korea. 2004. p 3.

Lee SY, Lee HS. The roles of dietary polyphenols in brain neuromodulation, Journal of Life Science. 2018. 28: 1386-1395.

Lim TK. Edible medicinal and non-medicinal plants. 2015. Volume 9. 1036. Springer Dordrecht Heidelberg New York, USA.
Park SJ, Park, Park DS, Lee SB, He XL, Ahn JH, Yoon WB, Lee HY. Enhancement of Antioxidant Activities of Codonopsis lanceolata and Fermented Codonopsis lanceolata by Ultra High Pressure Extraction. J Korean Soc Food Sci Nutr. 2010. 39: 1898-1902.

Perron NR, Brumaghim JL. A review of the antioxidant mechanisms of polyphenol compounds related to iron binding. Cell Biochem Biophys. 2009. 53: 75-100.

Rice-Evans C, Miller N, Paganga G. Antioxidant properties of phenolic compounds. Trends Plant Sci. 1997. 2: 152-159.

Seo YC, Choi WY, Kim JS, Cho JS, Kim YO, Kim JC, Lee HY. Enhancement of Anticancer Activities from Lithospermum erythrorhizon Extracts by Ultra High Pressure Process. Korean J. Medicinal Crop Sci. 2011. 19: 103-110.

Shouqin Z, Junjie Z, Changzhen W. Novel high pressure extraction technology. International Journal of Pharmaceutics. 2004. 278 : 471-474.

Singleton VL, Orthofer R, Lamuela-Raventós RM. Analysis of total phenols and other oxidation substrates and antioxidants by means of folin-ciocalteu reagent. Methods Enzymol. 1999. 299: 152-178.

Zhishen J, Mengcheng T, Jianming W. The determination of flavonoid contents in mulberry and their scavenging effects on superoxide radicals. Food Chem. 1999. 64: 555-559.

https://doi.org/10.15616/BSL.2021.27.4.291

Cite this article as: Kim EY, Jeon JW, Hyun KY. Comparison of Saponin Content and Antioxidant Effect depending on the Processing Method of Codonopsis lanceolata. Biomedical Science Letters. 2021. 27: 291297. 